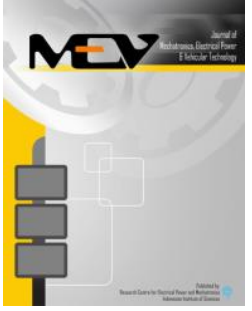

Journal of Mechatronics, Electrical Power, and Vehicular Technology

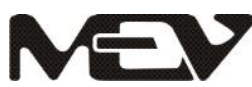

\title{
DESIGN AND IMPLEMENTATION OF CONTROLLER FOR BOOST DC-DC CONVERTER USING PI-LPF BaSed On SMall Signal Model
}

\author{
Slamet Kasbi a, c, Estiko Rijanto ${ }^{\text {b, *, Rasli bin Abd Ghani a }}{ }^{\text {a }}$ \\ ${ }^{a}$ Malaysia-Japan International Inst. Of Tech. (MJIIT), Universiti Teknologi Malaysia (UTM) Kuala Lumpur \\ Jalan Semarak, 54100 Kuala Lumpur, Malaysia \\ ${ }^{\mathrm{b}}$ Research Center for Electrical Power and Mechatronics, Indonesian Institute of Sciences (LIPI) \\ Kampus LIPI, Jalan Sangkuriang, Gd.20, Bandung 40135, Indonesia \\ ${ }^{c}$ Ministry of Energy and Mineral Resources (KESDM), Research and Development Agency (P3TKEBTKE) \\ Jl. Ciledug Raya Kav.109 Cipulir Kebayoran Lama, Jakarta 12230, Indonesia
}

Received 5 August 2015; received in revised form 17 September 2015; accepted 17 September 2015

Published online 30 December 2015

\begin{abstract}
Boost DC-DC converters are used in many renewable energy sources including photovoltaic and fuel cell. They are also used in Uninterrupted Power Supply, inverters, electric vehicles and robots. In this paper a boost converter was built and its controller was developed using proportional integral (PI) action for current loop and low pass filter (LPF) for voltage loop. The controller was derived analytically based on small signal model. Experiment results show that the boost controller functions well in regulating the output voltage under a variation of load. During the start up without any load it can elevate input voltage from $119.6 \mathrm{~V}$ to output voltage of $241.6 \mathrm{~V}$. The developed controller can regulate the output voltage smoothly under load variation from no load to sudden load of $352 \mathrm{~W}$. When a large sudden load change happens from $0 \mathrm{~W}$ to $1,042 \mathrm{~W}$ the output voltage experiences small drop before it is recovered to $241.6 \mathrm{~V}$. It can be concluded that the developed control system satisfies the design specification.
\end{abstract}

Keywords: controller; boost DC-DC converter; PI; LPF; small signal.

\section{INTRODUCTION}

A boost DC-DC converter functions to elevate a low level DC voltage to a higher level DC voltage. They are used in many renewable energy sources including photovoltaic and fuel cell. They are also used in Uninterrupted Power Supply (UPS), inverters, electric vehicles, and robots.

Many types of controllers for boost DC-DC converters have been proposed by other researchers. One type of the controller is a controller that was designed on the basis of Current Mode Control (CMC) and Linear Quadratic Regulator (LQR) [1]. It incorporates feedback gains of the LQR. The controller was designed so that the inductor current could follow any given reference current which could be the output of a Maximum Power Point Tracking (MPPT) algorithm. The method has been proved

\footnotetext{
* Corresponding Author.Tel: +62-22-2503055

E-mail: estiko.rijanto@lipi.go.id
}

through Matlab/Simulink simulation [1]. In other study, a repetitive controller was added to a proportional integral controller in current loop to lessen crossover distortion of input current as proved through computer simulation [2]. In a more recent study, an extended Kalman filter was proposed for inductor current estimation and output voltage filtering where a predictive average current control was used to regulate the current [3].

Experimental results showed that the transient response was improved compared to conventional voltage control system. Rao et al. (2013) used a proportional integral derivative (PID) controller without any current loop to directly control output voltage where its parameter values were determined by the use of Genetic Algorithm (GA) [4]. They concluded that GA provides better performance than Bacterial Foraging Algorithm (BFOA). Other studies proposed different approaches. A model predictive control (MPC) approach was used 
which could explicitly account for physical constraints on duty cycle and inductor current [5]. An approximate 2-Degrees-of-Freedom digital controller was proposed for suppressing the change of step response characteristics and variation of output voltage in the load sudden changes [6].

The load and output voltage changes are considered as parameter changes which are transformed to equivalent disturbances. The controller is constructed using model matching, inverse system and filter, and it has been examined and well-proved through experiment [6]. Control methods based on sliding mode have also been reported by many other researchers $[7,8]$. They demonstrated the effectiveness of their methods through computer simulations. Zakiyullah et al. (2012) used PI controller for a DC-DC bidirectional converter where its parameter values were determined through numerical simulation [9]. In other study by Seno Aji et al. (2013), Fuzzy controller was used for a boost DC-DC converter coupled with MPPT in a photovoltaic system for a solar car where its effectiveness was verified through computer simulation [10].

In this study, boost DC-DC converter was built and its controller was also designed. An analytical approach is used based on average small signal model. The converter is to elevate a DC voltage source from $120 \mathrm{~V}$ to $240 \mathrm{~V}$ with the power capacity of $4.5 \mathrm{~kW}$. To realize such a converter, a power electronic circuit was built using appropriately selected inductor, capacitor, MOSFET and other components. Then, a controller was designed to maintain the converter output voltage under load variations. To design the controller, firstly small signal dynamical model was derived.

The controller was composed of two control loops namely current control loop and voltage controller loop. The current controller was designed using proportional and integral (PI) actions while the voltage controller was designed using low pass filter (LPF) transfer function. Finally, the effectiveness of the developed control system was verified through an experiment.

Section 2 of this paper presents conceptual design, specification and dynamical modeling of the boost DC-DC converter. Section 3 is devoted to controller design of the boost DC-DC converter using simplified version of the derived dynamical model. Section 4 describes experiment results and discussion. Section 5 summarizes the conclusions.

\section{SPECIFICATION AND Modeling}

\section{A. Specification}

Figure 1 shows block diagram of the boost DC-DC converter control system developed in this study. This control system consists of a boost DC-DC converter and its controller. The boost converter was constructed from inductor, diode, capacitor, and switch which was equipped with its driver circuit. Other components shown in the figure are input filter, soft start circuit, and snubber.

A controller was designed to control the output voltage of the converter. It receives feedback signals including output voltage, input voltage, and input current. It computes error value between the voltage reference and ouput voltage signal, and then calculates modulated control pulse signal which is sent to the driver of the switch.

Table 1 shows the design specification of the boost DC-DC converter. This specification came from a real need to accommodate an inverter which converts $240 \mathrm{~V}$ DC to $220 \mathrm{~V}$ AC using $120 \mathrm{~V} \mathrm{DC}$ from a string of batteris. From this table it can be calculated that the inductor average current is $37.5 \mathrm{~A}$, and the nominal load is $12.8 \mathrm{Ohm}$.

\section{B. Modeling of the Boost DC-DC Converter}

The boost converter operates in two switching modes namely closed mode (switch on) and open mode (switch off). During the closed mode, the dynamics of the converter can be expressed in the following equations;

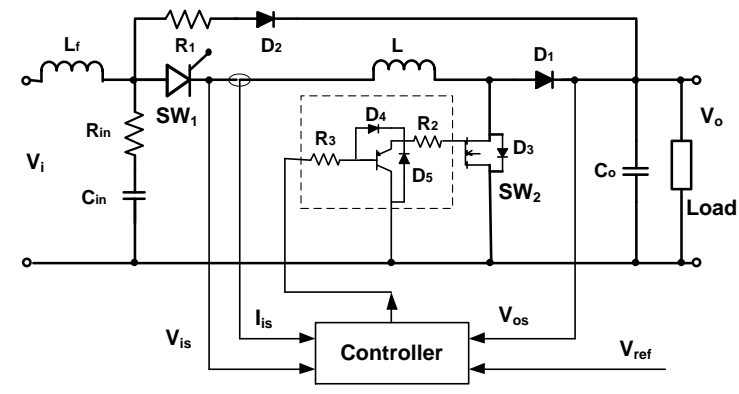

Figure 1. The developed boost converter control system

Table 1.

Specification of the boost converter

\begin{tabular}{lrl}
\hline Parameter & Value & Unit \\
\hline Maximum power, Pmax & 4,500 & $\mathrm{~W}$ \\
\hline Maximum input voltage, Vimax & 130 & $\mathrm{~V}$ \\
\hline Nominal input voltage, Vinom & 120 & $\mathrm{~V}$ \\
\hline Minimum input voltage, Vimin & 100 & $\mathrm{~V}$ \\
\hline Reference ouput voltage, Vref & 240 & $\mathrm{~V}$ \\
\hline Switching frequency, fs & 62,000 & $\mathrm{~Hz}$ \\
\hline
\end{tabular}




$$
\begin{aligned}
& L \frac{d i_{L}(t)}{d t}+r i_{L}(t)=V_{i} \\
& C \frac{d V_{o}(t)}{d t}+\frac{V_{O}(t)}{R}=0
\end{aligned}
$$

where the parameters $L, C, r$, and $R$ denote inductor, output capacitor, internal resistance of the inductor, and load resistor, respectively. The variable $s i_{L}, V_{o}$, and $V_{i}$ represent inductor current, output voltage, and input voltage.

The initial values of inductor current and output voltage are assumed to be $i_{L}(0)=i_{10}$ and $V_{o}(0)=V_{10}$. During open mode, the dynamics of the converter is given as follows;

$$
\begin{aligned}
& L \frac{d i_{L}(t)}{d t}+r i_{L}(t)+V_{o}(t)=V_{i} \\
& C \frac{d V_{o}(t)}{d t}+\frac{V_{o}(t)}{R}=i_{L}(t)
\end{aligned}
$$

The initial values of inductor current and output voltage are assumed to be $i_{L}(0)=i_{20}$ and $V_{o}(0)=V_{20}$.

The relationship among the time period of the switch being closed $t_{\text {on }}$, opened $t_{\text {off }}$ and switching period $T_{S}$ is given by the following equation.

$$
t_{\text {on }}+t_{\text {off }}=T_{s}=\frac{1}{f_{s}}
$$

In the steady state condition the following relationships hold;

$$
\begin{aligned}
& i_{20}=i_{L}\left(t_{\text {on }}\right) \\
& \left.i_{10}=i_{L}\left(t_{o f f}\right)\right\} \\
& V_{20}=V_{o}\left(t_{o n}\right) \\
& \left.V_{10}=V_{o}\left(t_{o f f}\right)\right\}
\end{aligned}
$$

Furthermore, under ideal condition without energy losses, the total energy transferred from the energy source to the output capacitor through the inductor during switch off is the same as that which is saved into the inductor during switch on. This yields the following equation;

$$
\frac{V_{o}}{V_{i}}=\frac{T_{S}}{t_{o f f}}=\frac{T_{S}}{T_{S}-t_{o n}}=\frac{1}{1-D}
$$

where $D$ denotes duty ratio. Given input voltage and output voltage values in the specification listed in Table 1 , the nominal duty ratio of 0.5 is obtained.

After some calculation from the dynamics equations in (1)-(4) the following average small signal model is obtained:

$$
\left[\begin{array}{l}
\dot{x}_{1} \\
\dot{x}_{2}
\end{array}\right]=\left[\begin{array}{cc}
0 & \frac{-(1-D)}{L} \\
\frac{(1-D)}{C} & \frac{-1}{R C}
\end{array}\right]\left[\begin{array}{l}
x_{1} \\
x_{2}
\end{array}\right]+\left[\begin{array}{c}
\frac{V_{O}}{L} \\
\frac{-I_{L}}{C}
\end{array}\right] \hat{d}+\left[\begin{array}{c}
\frac{1}{L} \\
0
\end{array}\right] \hat{v}_{i}
$$

where $x_{1}$ is small deviation of current value around its nominal value $x_{2}$ is small deviation of output voltage value around its nominal value $\hat{d}$ and $\hat{v}_{i}$ represent deviation of duty ratio around nominal value and the deviation of input voltage value around its nominal value, respectively.

The internal resistance of the inductor is assumed to be much smaller than the inductance so that the following relationship can be derived from equation (1).

$$
L \frac{\Delta i_{L}}{t_{o n}}=V_{i} \Rightarrow L=\frac{V_{i}}{\Delta i_{L}} \frac{D}{f_{s}}
$$

where $\Delta i_{L}$ represents inductor current ripple. By specifying acceptable current ripple value, from equation (10) the value of inductance can be determined. In this paper the values of inductance and output capacitor are selected to be $129 \mu \mathrm{H}$ and $2.15 \mathrm{mF}$.

\section{CONTROLLER DESIGN}

From the average small signal model in equation (9) the following transfer functions can be derived:

$$
\begin{aligned}
& P_{1}(s)=\frac{x_{1}(s)}{\widehat{d}(s)}=\frac{\left(C V_{O}\right) s+2(1-D) I_{L}}{(L C) s^{2}+\frac{L}{R} s+(1-D)^{2}} \\
& P_{2}(s)=\frac{x_{2}(s)}{\widehat{d}(s)}=\frac{(1-D) V_{O}-\left(L I_{L}\right) s}{(L C) s^{2}+\frac{L}{R} s+(1-D)^{2}}
\end{aligned}
$$

$P_{1}(s)$ and $P_{2}(s)$ express transfer functions from duty ratio to inductor current and from duty ratio to output voltage of the boost converter. Obviously, it seems from equation (12) that the simplest way to control the output voltage of the converter is by using duty ratio as the control input. However, the transfer function in equation (12) has zero in the Right Hand Side. It is difficult to design linear controller which can satisfy small overshoot and fast time response specification. An alternative method is needed to design an appropriate controller.

From equation (11) it is noticeable that the inductor current may be controlled using duty ratio as the control input. Therefore, another method to control the output voltage of the converter is by using inductor current as the control input. From equations (11) and (12) the following transfer function can be derived;

$$
P_{3}(s)=\frac{x_{2}(s)}{x_{1}(s)}=\frac{(1-D) V_{O}-\left(L I_{L}\right) s}{\left(C V_{O}\right) s+2(1-D) I_{L}}
$$

Similar to equation (12), this transfer function also has zero in the Right hand Side which make it difficult to obtain good result using only linear feedback control. Therefore, as an alternative method in this study in order to control the output voltage of the boost DC-DC converter two control loops are incorporated using current control loop in the inner loop and voltage control loop in the outer control loop. Some assumptions were set to make it easier in designing both current controller and voltage controller. 


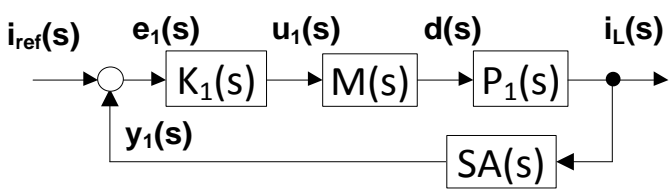

Figure 2. The designed current control loop

Figure 2 shows the current control loop which is designed in this study. Current controller $K_{1}(s)$ is designed so that the inductor current $i_{L}(s)$ follows the given reference current $i_{\text {ref }}(s)$. The current controller $K_{1}(s)$ receives current feedback signal $y_{1}(s)$ from the current sensor $S A(s)$. The current controller produces command signal $u_{1}(s)$ to the Pulse Width Modulator (PWM) $M(s)$, then the PWM sends pulse command duty $d(s)$ to the switch of the boost DC-DC converter.

A current sensing circuit was developed. Based on experiment results, its relationship is given by the following equation;

$$
y_{1}(t)=-0.007 i_{L}(t)-0.364
$$

Pulse width modulation is realized using saw tooth signal as given below;

$$
v_{M}(t)=v_{L}+\left(v_{U}-v_{L}\right) \frac{t}{T_{S}}
$$

where $v_{U}$ and $v_{L}$ represent upper voltage limit and lower voltage limit of the modulation signal $v_{M}(t)$. In this paper, the upper voltage limit and the lower voltage limit are set to be $6.3 \mathrm{~V}$ and 1.3 $\mathrm{V}$, respectively. The peak to peak value of the modulation signal $V_{m p p}$ is $5 \mathrm{~V}$. Thus, transfer function of the modulator is given as follows;

$$
M(s)=\frac{1}{V_{m p p}}=0.2
$$

from equations (11), (14) and (16) the total transfer function $P_{1 T}(s)$ from current control input $u_{1}(s)$ to current feedback signal $y_{1}(s)$ can be derived as follows;

$$
P_{1 T}(s)=\frac{-2.5 \cdot 10^{3}(s+72,6)}{s^{2}+36.3 s+900.3 \cdot 10^{3}}
$$

In this study, a current controller was designed using proportional and integral actions as below. This current controller is equipped with a low pass filter to filter out noise due to high frequency switching.

$$
K_{1}(s)=\left[K_{p}+\frac{K_{i}}{s}\right]\left[\frac{1}{\frac{1}{\omega p} s+1}\right]
$$

Determining controller parameters values in equation (18) based on transfer function in equation (17) is rather complicated. In order to make it easier to calculate the controller parameter values, it was assumed that the

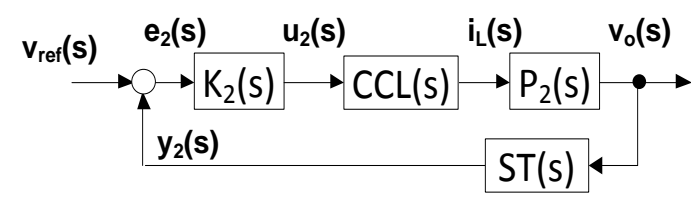

Figure 3. The designed voltage control loop

deviation values of both input voltage and output voltage were substantially smaller than the value of output voltage itself. Thus from the small signal model in equation (9) the effect of both the deviation values to the current can be neglected. As a result, the total transfer function $P_{1 T}(s)$ from current control input $u_{1}(s)$ to current feedback signal $y_{1}(s)$ can be simplified as below;

$$
P_{1 T n}(s)=\frac{\alpha_{1}}{s}
$$

Upon obtaining the simplified transfer function in equation (19), the current controller parameter values in equation (18) are determined. By setting cross over frequency value $\omega_{c}$ and phase angle margin value $\alpha$, the current controller parameter values can be calculated using unity gain and phase angle margin relationships as commonly known in the conventional control theory based of frequency domain.

$$
\begin{aligned}
& \left|K_{1}(s) P_{1 T n}(s)\right|_{s=j \omega_{c}}=1 \\
& \tan \left(K_{i}+K_{p} s\right)_{s=j \omega_{c}}=\tan (\alpha-\pi)
\end{aligned}
$$

The low pass filter parameter value $\omega_{p}$ is selected to suppress high frequency switching noise. Table 2 shows an example of current controller parameter values $\left(K_{p}, K_{i}, \omega_{p}\right)$ obtained using the above approach.

The next step is designing a voltage controller. Figure 3 shows voltage control loop used in this paper. The voltage controller $K_{2}(s)$ is designed so that output voltage $V_{o}(s)$ tracks the given reference value $V_{r e f}(s)$. The voltage controller $K_{2}(s)$ receives feedback signal $y_{2}(s)$ from the voltage sensor $S T(s)$. The controller sends command signal $u_{2}(s)$ to the current control loop $\operatorname{CCL}(s)$, in turn current $i_{L}(s)$ is delivered to $P_{2}(s)$ to control the output voltage $V_{o}(s)$. For the sake of simplicity, it was assumed that the current control loop works well and that it was much faster than the voltage control loop. By imposing

Table 2.

An Example of current controller parameter values

\begin{tabular}{lrl}
\hline Parameter & Value & Unit \\
\hline Proportional gain: $K_{p}$ & 3.06 & - \\
\hline Integral gain: $K_{i}$ & 36773 & - \\
\hline Low pass filter frequency: $\omega_{p}$ & 65940 & $\mathrm{Rad} / \mathrm{sec}$ \\
\hline
\end{tabular}


this assumption into the average small signal model, the following simplified transfer function from inductor current to output voltage can be derived;

$$
P_{2}(s)=\frac{\beta_{1}}{s+\beta_{2}}
$$

By observing equation (22), in this study a controller is designed of the form low pass filter (LPF). The parameter values of the controller were determined by taking into account the desired cut off frequency, steady state error and oscillation damping. After some calculation, the following output voltage controller $K_{2}(s)$ is obtained.

$$
K_{2}(s)=\frac{88556}{s+708}
$$

\section{IMPLEMENTATION RESULTS AND DISCUSSION}

Figure 4 shows a photo of the developed boost DC-DC converter. High frequency switching is realized using $\mathrm{N}$-Channel power MOSFET IXFH50N60P3 while the soft start switch uses Thyristor SKKL 92. The controller is realized using both analog and digital circuits.

Some experiments have been conducted in order to verify the effectiveness of the developed boost DC-DC converter control system. The power source was realized using 10 Lead Acid batteries connected in series to provide $120 \mathrm{~V}$ input voltage. Each battery has the capacity of 45 Ah. Experiments were carried out in some cases including start up without load and sudden load variations $(352 \mathrm{~W}, 1,042 \mathrm{~W}$, and 1,393 W). Signals of concern were measured using available oscilloscope and multi tester.

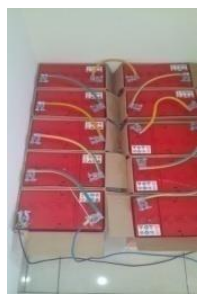

(a)

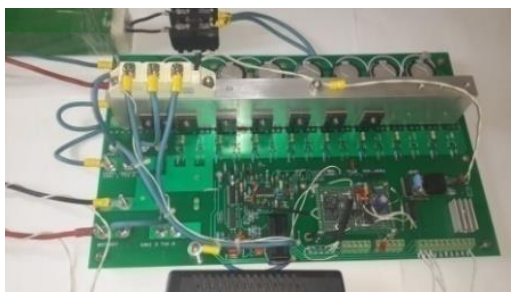

(b)
Figure 4. The developed boost DC-DC converter; (a) Battery string; (b) Boost DC-DC converter

Figure 5 shows the experimental result when the boost converter starts working. The horizontal axis indicates time in second and the vertical axis is voltage in Volt from each sensor. The red line represents output voltage of the boost converter while the blue line expresses inductor current. From this figure it can be noted that the boost converter could elevate the output voltage from initial value around $120 \mathrm{~V}$ to steady state voltage around $240 \mathrm{~V}$. This happens because the controller generates pulses command which is reflected in the inductor current ripple as shown in the figure. After having reached the steady state condition the controller stops generating pulses command continuously. It only produces pulses command when it is needed to compensate power losses.

Figure 6 to 9 show the experimental results when the boost DC-DC converter is loaded with certain load. The horizontal axis indicates time in second and the vertical axis is voltage in Volt from each sensor. Figure 6 demonstrates experimental result when the converter is suddenly loaded with a small halogen lamp. The red line represents output voltage while the blue line expresses inductor current. It can be seen that

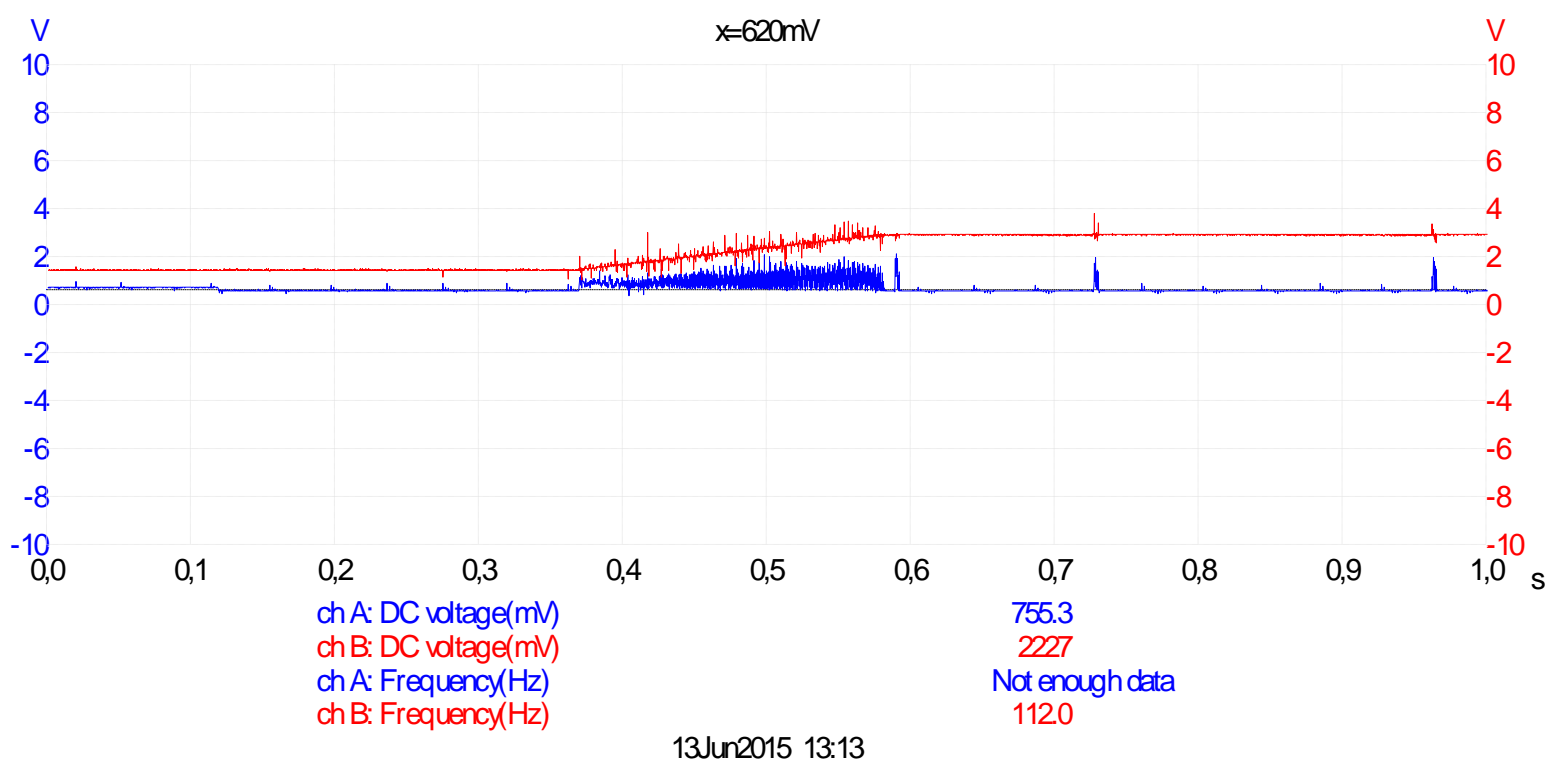

Figure 5. Output voltage response during start up 
the output voltage is maintained at constant value. At the instant when the load is added a quite small voltage drop exists but it is soon recovered to the reference value. Large current rise indicates the effort of the controller to compensate the sudden voltage drop. Under loaded condition, the controller continuously sends pulse width modulator command to deliver current from the energy source to the load while maintaining the output voltage at the reference value. The average current flowing through the inductor at the steady state condition was around $0.576 \mathrm{mV}$ which corresponded to $2.94 \mathrm{~A}$. Measurement using a multi meter showed that at the steady state under the load, the input and ouput voltages were $119.6 \mathrm{~V}$ and $241.6 \mathrm{~V}$ respectively. Thus the power quantity of the small halogen lamp was around $352 \mathrm{~W}$.
Figures 7 and 8 demonstrate experimental result when the converter was suddenly loaded with a large halogen lamp. In Figure 7, the red line represents output voltage of the boost converter while the blue line expresses inductor current. At the instant when the load was added to the converter a voltage drop existed but it was gradually recovered. Once a large current rise was noticeable but it soon diminished since the current protection mechanism took place to protect the system. After a while the current rises again to compensate the voltage drop. Under loaded condition, the controller continuously sends pulse width modulator command to deliver current from the energy source to the load while maintaining the output voltage at the reference value. The average current flowing through the inductor at the steady state condition was around

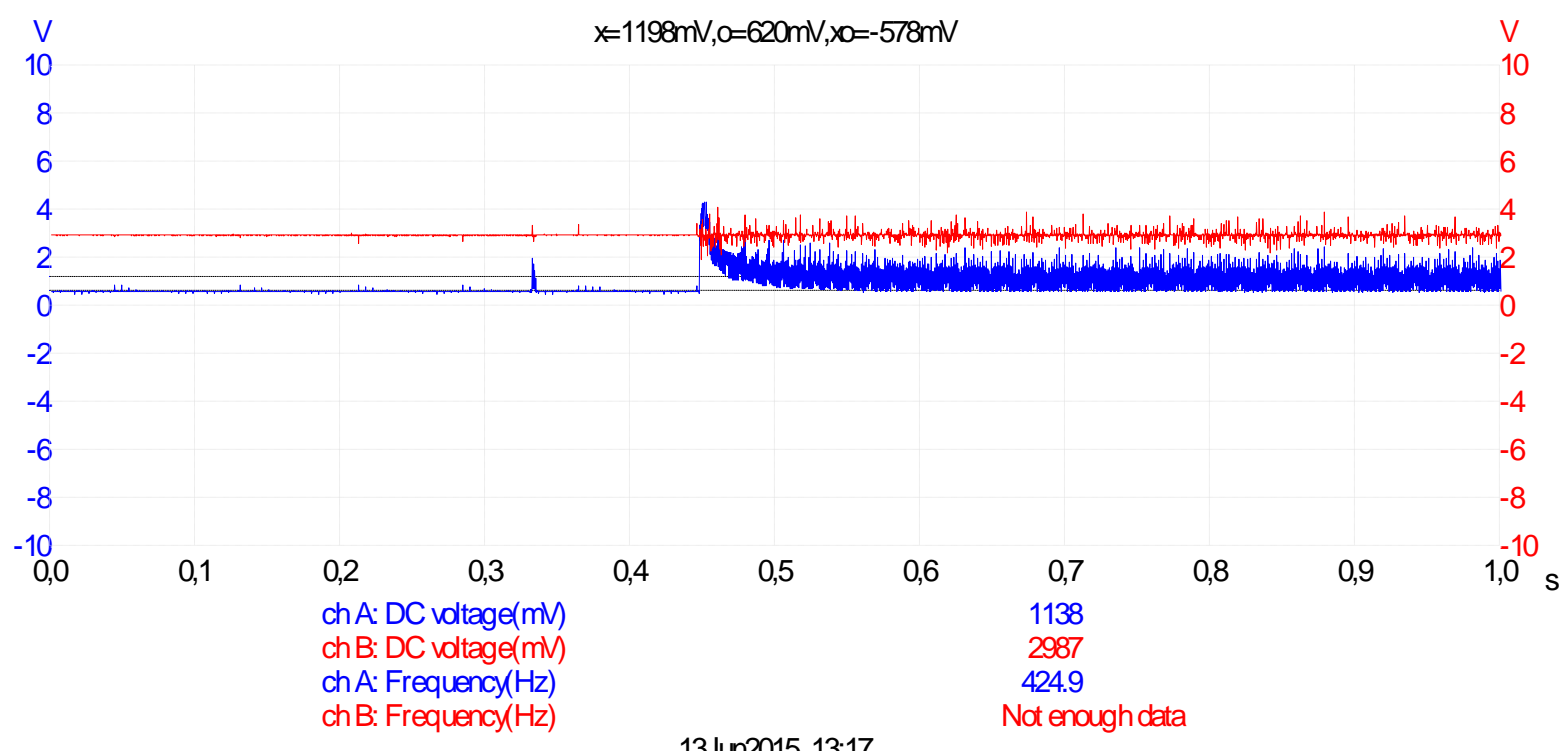

Figure 6. Ouput voltage and inductor current under small halogen lamp load

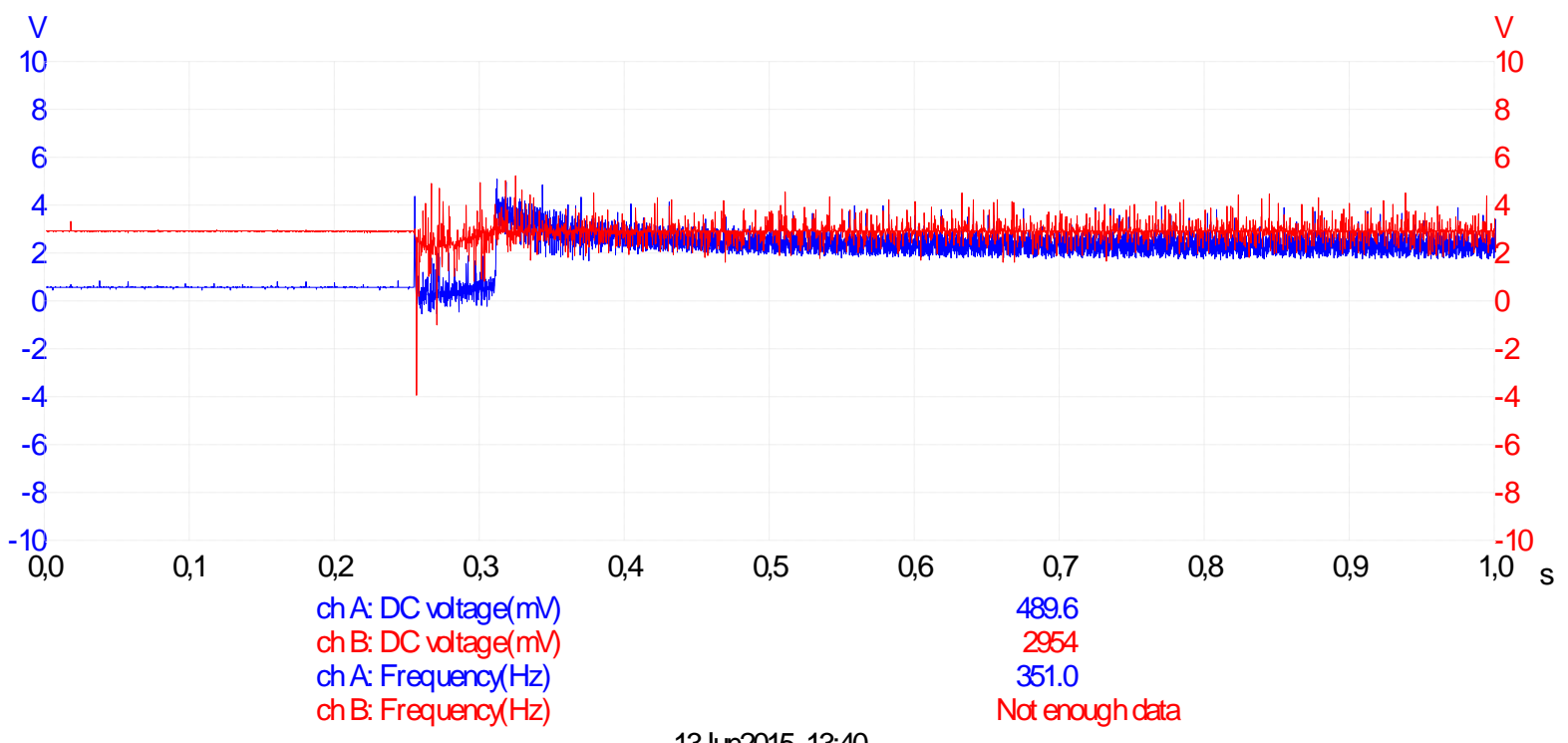

13Jun2015 13:40

Figure 7. Ouput voltage and inductor current under large halogen lamp load 
8.71 A. Measurement using a multi meter showed that at the steady state under the load, the voltage input was $119.6 \mathrm{~V}$ and the voltage output was $241.6 \mathrm{~V}$. The power of the large halogen lamp was around 1,042 W.

In Figure 8 the red line shows pulse width modulation output of the controller while the blue line demonstrates inductor current under steady state condition with load. It can be noted that when the switch was closed (PWM "high") the inductor current rose, oppositely when the switch was open (PWM "low") the inductor current went down. This result demonstrates that the controller works in continuous current mode control. The switching frequency was around $62.33 \mathrm{kHz}$ and the period of switch on was around $8.22 \mu \mathrm{s}$ which corresponded to duty ratio of $51.2 \%$.

Figure 9 shows experimental result when the converter is loaded with the large and the small halogen lamp in parallel concurrently. The red line shows pulse width modulation output of the controller while the blue line demonstrates inductor current under steady state condition. When the switch was closed (PWM "high") the inductor current rose, oppositely when the switch was open (PWM "low") the inductor current went down. The average inductor current was around 11.65 A which corresponded to $1,393 \mathrm{~W}$. The switching frequency was around $62.42 \mathrm{kHz}$ and the period of switch on was around $8.37 \mu \mathrm{s}$ which corresponded to duty ratio of $52.2 \%$.

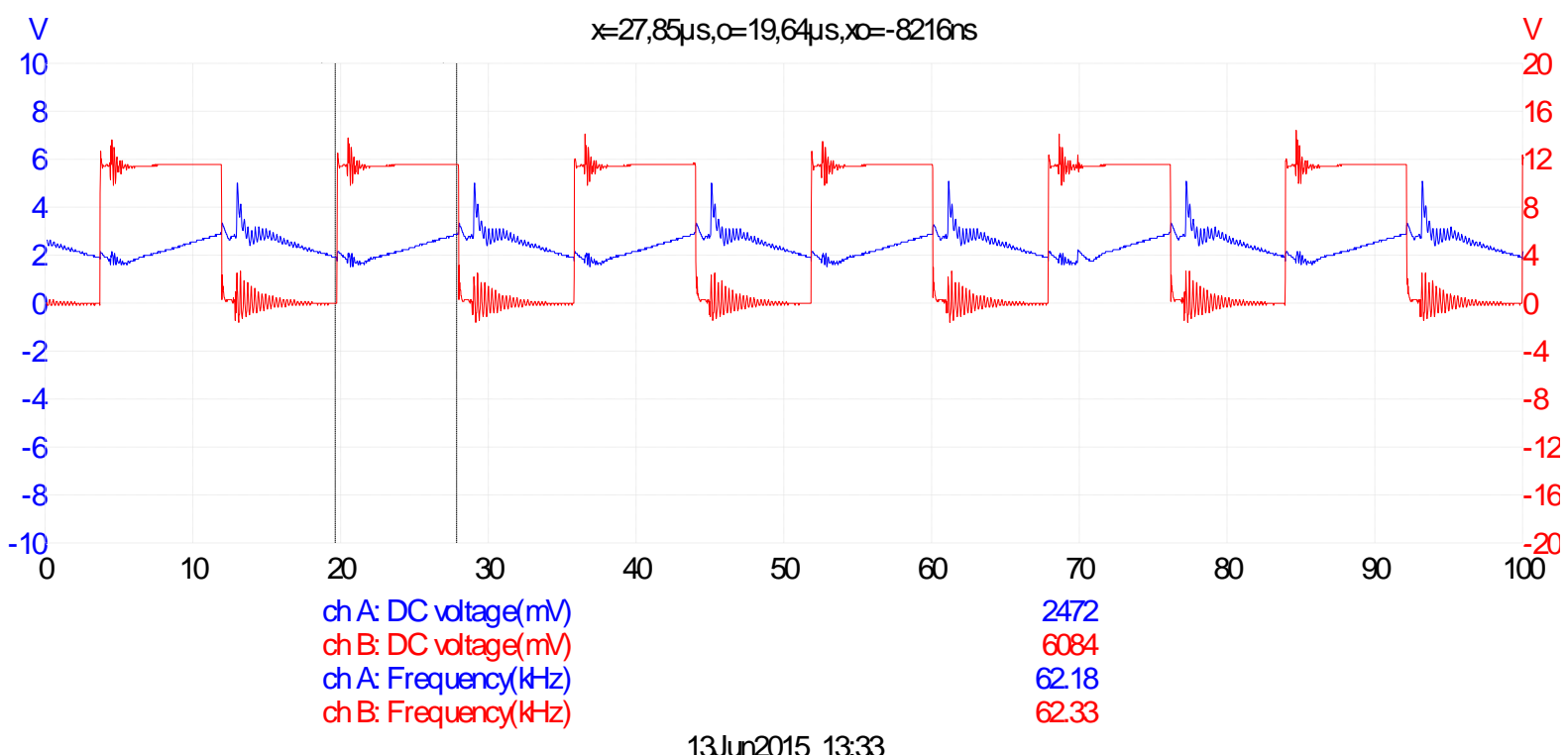

Figure 8. Controller output PWM and inductor current under large halogen lamp load

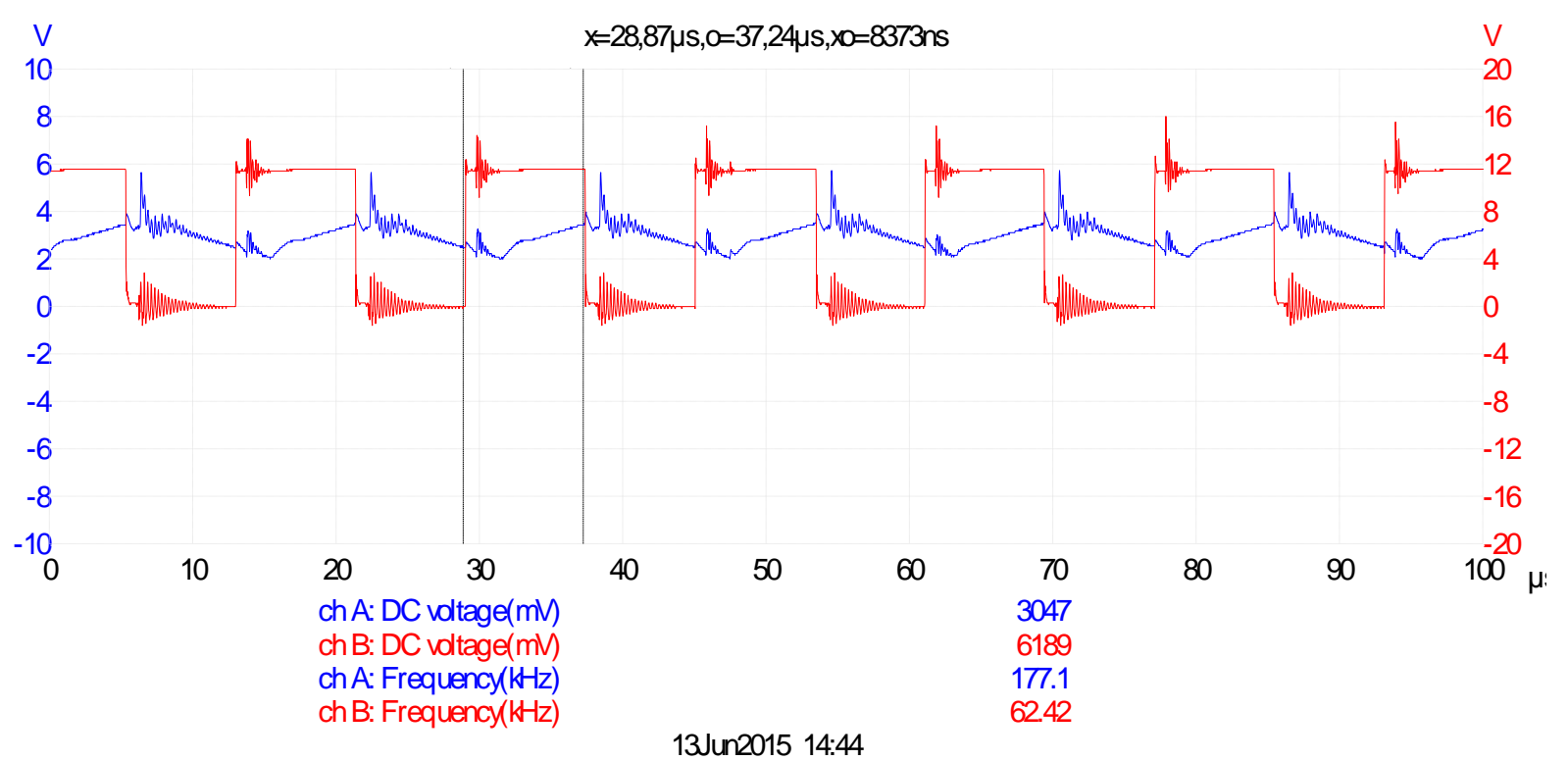

Figure 9. Controller output PWM and inductor current under load of the large and small halogen lamps in parallel 
There was no much difference in duty ratio between these two cases. This is because the ratio between output voltage and input voltage were almost the same. These experiment results are in line with equation (8).

\section{Conclusion}

From the experimental results the following conclusion can be drawn. During the start up without any load the developed boost DC-DC converter can elevate input voltage of $119.6 \mathrm{~V}$ to output voltage of $241.6 \mathrm{~V}$. The developed controller can regulate the output voltage of the boost converter smoothly under load variation from no load to sudden load of $352 \mathrm{~W}$. These results prove that the PI controller in the current loop and the LPF controller in the voltage loop work well. When large sudden load change happens from $0 \mathrm{~W}$ to $1,042 \mathrm{~W}$ the output voltage experiences small drop wich proves that the current protection works well. Afterwards the ouput voltage is recovered to $241.6 \mathrm{~V}$. There is no significant difference of duty ratio between different conditions under load variations in steady state condition. This is because the ratio between the output voltage and the input voltage is almost the same. It can be concluded that the developed control system satisfies the design specification.

\section{ACKNOWLEDGEMENT}

The authors thank to Universiti Teknologi Malaysia (UTM) Kuala Lumpur, the Indonesian Institute of Sciences (LIPI), and the Ministry of Energy and Mineral Resources of the Republic of Indonesia for providing conducive circumstances to carry out this research activity.

\section{REFERENCES}

[1] M.A. Abdullah et al., "Input Current Control of Boost Converters using Current-Mode Controller Integrated with Linear Quadratic Regulator," International Journal of Renewable Energy Research, vol. 2, no.2, pp.262-268, 2012.

[2] T.K. Hassan, "A Repetitive PI Current Controller for Boost Single Phase PFC
Converters", Energy and Power Engineering, vol.3, pp.69-78, 2011.

[3] Q. Tong et al., "A Sensorless Predictive Current Controlled Boost Converter by Using an EKF with Load Variation Effect Elimination Function", Sensors, vol.15, pp.9986-10003, 2015.

[4] G.S. Rao et al., "Design of Feedback Controller for Boost Converter Using Optimization Technique", International Journal of Power Electronics and Drive System, vol.3, no.1, pp.117-128, 2013.

[5] A.G. Beccuti et al., "Optimal Control of the Boost DC-DC Converter", Proceedings of the $44^{\text {th }}$ IEEE Conference on Decision and Control, and the European Control Conferences, Spain, Dec.12-15, pp.44574462, 2005.

[6] Yoshihiro and K. Higuchi, "Robust Digital Control for Boost DC-DC Converter," Transactions on Electrical Engineering, Electronics, and Communications, vol. 10, no.1, pp. 68-73, 2012.

[7] H. Sira-Ramirez and M. Rios-Bolivar, "Sliding Mode Control of DC-to-DC Power Converters via Extended Linearization," IEEE Transactions on Circuits and SystemsI: Fundamental Theory and Applications, vol. 41, no.10, pp. 652-661, 1994.

[8] B. Allaoua et al., "A Robust Fuzzy Sliding Mode Controller Synthesis Applied on Boost DC-DC Converter Power Supply for Electric Vehicle Propulsion System," International Journal of Vehicular Technology, vol. 2013.

[9] M.Z. Romdlony and Amin, "Design and Implementation of Anti-Windup PI Control on DC-DC Bidirectional Converer for Hybrid Vehicle Applications," Journal of Mechatronics, Electrical Power and Vehicular Technology, vol. 3, no.1, pp.31-38, 2012.

[10] S. Aji et al., "MPPT Based on Fuzzy Logic Controller for Photovoltaic System in Solar Car,", Journal of Mechatronics, Electrical Power and Vehicular Technology, vol. 4, no.2, pp.127-134, 2013. 